\title{
Effect of inoculum morphology on production of Nigerloxin by solid state fermentation
}

\author{
VASANTHA, K. Y., SALEEM JAVEED, CHAKRADHAR, D. and SATTUR, A. P.* \\ Fermentation Technology and Bio Engineering Department Central Food Technological Research Institute Mysore, \\ 570020 India.
}

Received 16 October, 2013; Accepted 28 January, 2014

\begin{abstract}
Nigerloxin (2-amido-3-hydroxy-6-methoxy-5-methyle-4-(prop-1'enyl) benzoic acid) is a Lipoxygenase and Aldose reductase inhibitor produced by Aspergillus niger MTCC 5116. It is produced only under solid state fermentation (SSF) and the inoculum required for the inhibitor production is developed in submerged condition. As this is a newly discovered enzyme inhibitor with potential commercial success against diabetic complications, such as neuropathy and cataract, its complete fermentation process parametric study is not reported. In this study, the role of physical parameters (spore suspension, initial $\mathrm{pH}$, incubation temperature and agitation) in spore germination and pellet size in inoculum development broth in submerged fermentation for the enhanced production of nigerloxin through SSF has been studied. It was concluded that $500 \mu \mathrm{l}$ of spore suspension in the inoculum development broth at $\mathrm{pH} 7$, incubated at $30^{\circ} \mathrm{C}$ and $200 \mathrm{rpm}$ gave an ideal pellet size $1.23 \mathrm{~mm}$ resulting in $6.0 \mathrm{mg}$ of nigerloxin/g dry weight of wheat bran in SSF.
\end{abstract}

Key words: Nigerloxin, spore germination, solid state fermentation, Aspergillus niger.

\section{INTRODUCTION}

Inoculum development is one of the major unit operations in a fermentation process, involving production of required quantity of viable desired microbial biomass in its most productive state (Hockenhull, 1980). There are successful commercial fermentations using pellets and others use dispersed forms. Much information exists on inoculum development for submerged fermentations. In fungal solid state fermentation, the thin line between success and failure of a productive fermentation process is the quality of biomass produced as inoculum. Unlike bacteria, fungal inoculum can be manipulated to required pellet sizes or suspension forms through physical fermentation parameters to subsequently yield large quantities of the product in the main fermentation process. Further, not many reports exist on the influence of physical parameters on the fungal morphology in inoculum development broth on the production of desired metabolites through solid state fermentation.

Nigerloxin, produced by solid state fermentation of Aspergillus niger MTCC 5116 on wheat bran medium, is a Lipoxygenase and Aldose reductase inhibitor (Rao et al., 2002). It shows beneficial effects against diabetic

*Corresponding author. E-mail: asattur@cftri.res.in. Tel: +91-821-2515792. Fax: +91-821-2517233.

Author(s) agree that this article remain permanently open access under the terms of the Creative Commons Attribution License 4.0 International License 
<smiles>C/C=C/c1c(C)c(OC)c(C(N)=O)c(C(=O)O)c1O</smiles>

Figure 1. Structure of nigerloxin

complications such as oxidative stress and cataract formation in vivo (Suresh et al., 2012; Suresh et al., 2013). Production of nigerloxin is associated with the sporulation of the organism in SSF. The fermentation process is not completely reported for this potential commercially successful inhibitor against diabetic complications. While we have earlier described conditions for its optimum production (Chakradhar et al., 2009), here, we report the effect of physical parameters on inoculum by submerged fermentation and its subsequent production of nigerloxin in SSF.

\section{MATERIALS AND METHODS}

\section{Culture}

Aspergillus niger MTCC 5116 used in the present study was maintained on potato dextrose agar (Hi Media, Mumbai, India), at $4^{\circ} \mathrm{C}$ and subcultured once in every three weeks.

\section{Solid state fermentation}

Experiments were conducted in $500 \mathrm{ml}$ Erlenmeyer flasks containing $10 \mathrm{~g}$ of wheat bran supplemented with $5 \%(\mathrm{w} / \mathrm{w})$ trisodium citrate with an initial moisture content of $60 \%$. This medium served as a control wheat bran medium. After a thorough mixing, the flasks were autoclaved at $121^{\circ} \mathrm{C}$ for $1 \mathrm{~h}$, cooled to room temperature and $2 \mathrm{ml}$ of $A$. niger MTCC 5116 cell suspension was inoculated and incubated at $30^{\circ} \mathrm{C}$ for 6 days (Rao et al., 2005).

\section{Extraction and determination of nigerloxin}

At the end of fermentation, $100 \mathrm{ml}$ of ethyl acetate was added to the fermented bran and kept on a rotary shaker at $200 \mathrm{rpm}$ for $2 \mathrm{~h}$. The bran was then filtered through cheesecloth followed by Whatman No 1 filter paper. The solvent was evaporated to yield a crude extract. $1.36 \mathrm{~g}$ of crude was suspended in $25 \mathrm{ml}$ of chloroform and centrifuged at $2000 \mathrm{rpm}$ for 20 min to obtain an orange precipitate. This was resuspended in $50 \mathrm{ml}$ of warm ethanol to which $200 \mathrm{mg}$ of activated charcoal was added. This content was filtered through Whatman No 1 filter paper and concentrated to obtain nigerloxin, which was used as standard. The nigerloxin concentration in samples was determined at $292 \mathrm{~nm}$ in UV-VIS spectrophotometer (Shimadzu UV 1601) (Rao et al., 2002)

\section{Spore germination count}

The spores from three day old slant were scraped and suspended in $4 \mathrm{ml}$ of $2 \%$ Tween $20(\mathrm{v} / \mathrm{v})$ solution for several minutes to facilitate wetting, and centrifuged for $1 \mathrm{~min}$ at $4000 \mathrm{rpm}$. The supernatant was then poured off and the spores resuspended in 2 $\mathrm{ml}$ distilled water. This suspension was then added to $5 \mathrm{ml}$ of inoculum broth. Germination was determined based on the number of empty spore cases counted at $12^{\text {th }}$ hour of growth using a Spencer Bright-Line Haemocytometer (American Optical Company) under magnifications of 10X and 40X and expressed as percentage spore germination (Braun, 1971).

\section{Fungal pellet measurement}

Fungal pellets grown in inoculum broth were collected and the measurements of fungal pellets were done either directly under microscope or a centimetre scale on a digital photograph projection (Pazouki and Panda, 2000).

\section{Optimization of inoculum development parameters}

To optimize the inoculum development parameters several media components and cultural conditions were altered in submerged condition. The inoculum produced was inoculated to controlled wheat bran media and observed for the enhanced production of nigerloxin: 1) The effect of various standard media like potato dextrose broth, oatmeal broth, czapeckdox broth, tryptone yeast extract broth, modified egg yolk broth, yeast extract malt extract broth, potassium tellurite broth, and glycerol asperagin broth on the production of inoculum was studied by inoculating loopful $\left(5 \times 10^{5}\right.$ spores) A. niger CFR-W-105 to each broth and pellet morphology, media pigmentation, spore germination and biomass production was studied. Nigerloxin production was evaluated by using inoculum developed by each standard medium and inoculating on to controlled wheat bran media; 2) the effect of initial $\mathrm{pH}$ of the inoculum development broth on biomass production, pellet size and spore germination was determined by altering the initial $\mathrm{pH}$ of the fermentation media with the addition of acid or alkali. Nigerloxin production was evaluated by using inoculum developed by each $\mathrm{pH}$ range and inoculating on to controlled wheat bran media; 3) effect of temperature was studied by incubating the organism at various temperatures ranging from 10 to $50^{\circ} \mathrm{C}$ in inoculum development broth. The nature of pellets, rate of spore germination, biomass production and nigerloxin production was studied; 4) The effect of agitation condition on the development of pellet size, spore germination, biomass production and nigerloxin production was studied by incubating the inoculated flasks at various agitation conditions on a rotary shaker. Nigerloxin production was evaluated by inoculating the inoculum developed under all temperature ranges.

\section{RESULTS AND DISCUSSION}

Nigerloxin (2-amino-3hydroxy-6-methoxy-5-methyl-4(prop-1'-enyl) benzoic acid) (Figure 1) with a molecular weight of 265 and molecular formula $\mathrm{C}_{13} \mathrm{H}_{15} \mathrm{NO}_{5}$ was discovered in our laboratory as a potent inhibitor of rat eye lens aldose reductase and lipoxygenase with a free radical scavenging property. The inhibitor is produced only by solid state fermentation and not in submerged 


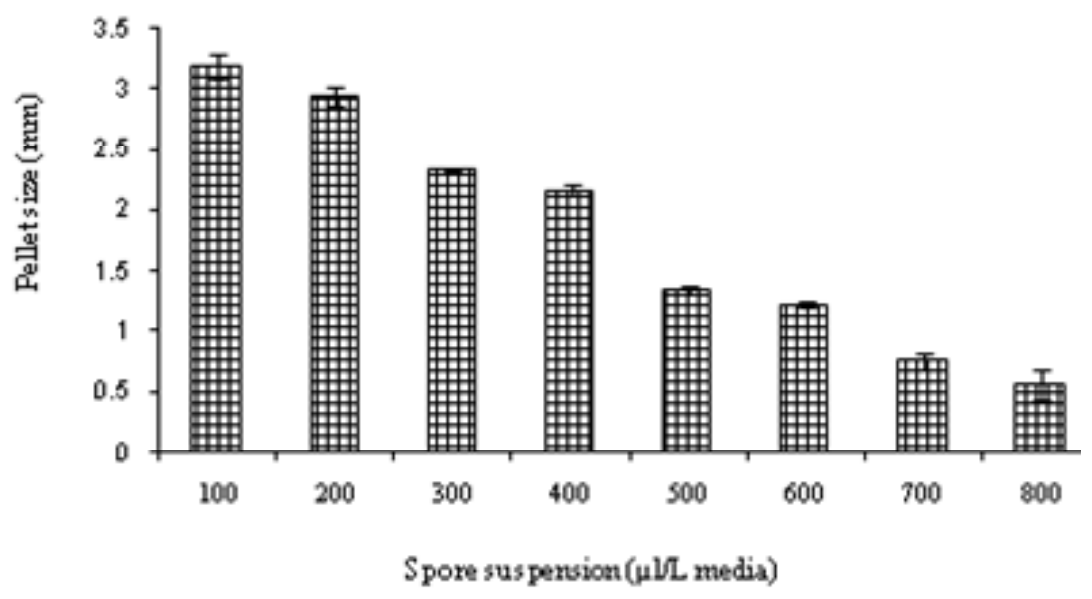

Figure 2a. Effect of spore suspension on pellet size.

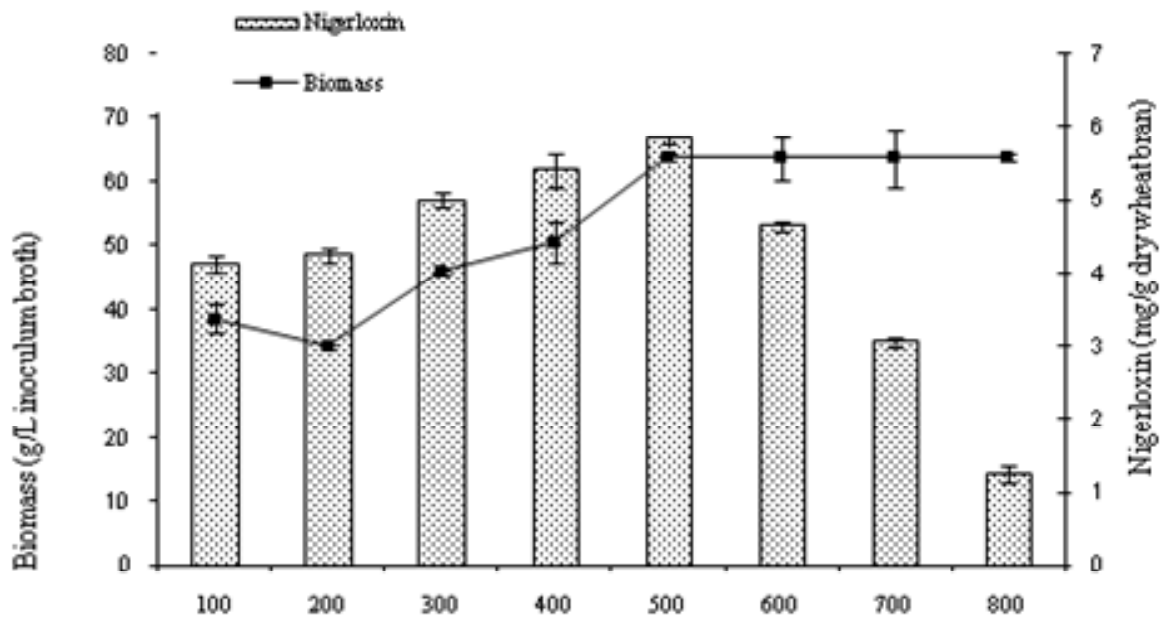

Spore suspension ( $\mu 1 \mathrm{lL}$ inoculumbroth)

Figure 2b. Effect of spore suspension on biomass of inoculums and nigerloxin production by SSF.

fermentation conditions and the production of the inhibitor is directly related to sporulation of the culture (Chakradhar et al., 2009).

\section{Optimization of physical parameters of inoculum}

For these studies, Czapekdox broth with $6 \mathrm{~g} / \mathrm{L}$ yeast extract was used as the inoculum medium since it showed good production compared to other nutritional media and solid state fermentation using wheat bran medium with $5 \%$ trisodium citrate, for the evaluation of nigerloxin production.

\section{Effect of spore suspension}

The amount of spores provided to a particular media in submerged fermentation condition has a direct impact on the morphology of pellets developed (Papagianni and Moo-Young, 2002). Increasing spore suspension from $100 \mu \mathrm{l} / \mathrm{L}$ inoculum broth to $800 \mu \mathrm{l} / \mathrm{L}$ inoculum broth showed a steady decrease in pellet size (Figure 2a). Spore suspensions below $400 \mu \mathrm{l} / \mathrm{L}$ media showed pellets sized above $2.1 \mathrm{~mm}$ which were not ideal for nigerloxin production in SSF (Figure $2 \mathrm{~b}$ ) perhaps as these yielded a biomass below $50 \mathrm{~g} / \mathrm{L}$. Spore suspensions greater than $700 \mu \mathrm{l} / \mathrm{L}$ produced smaller pellets perhaps due to lack of 


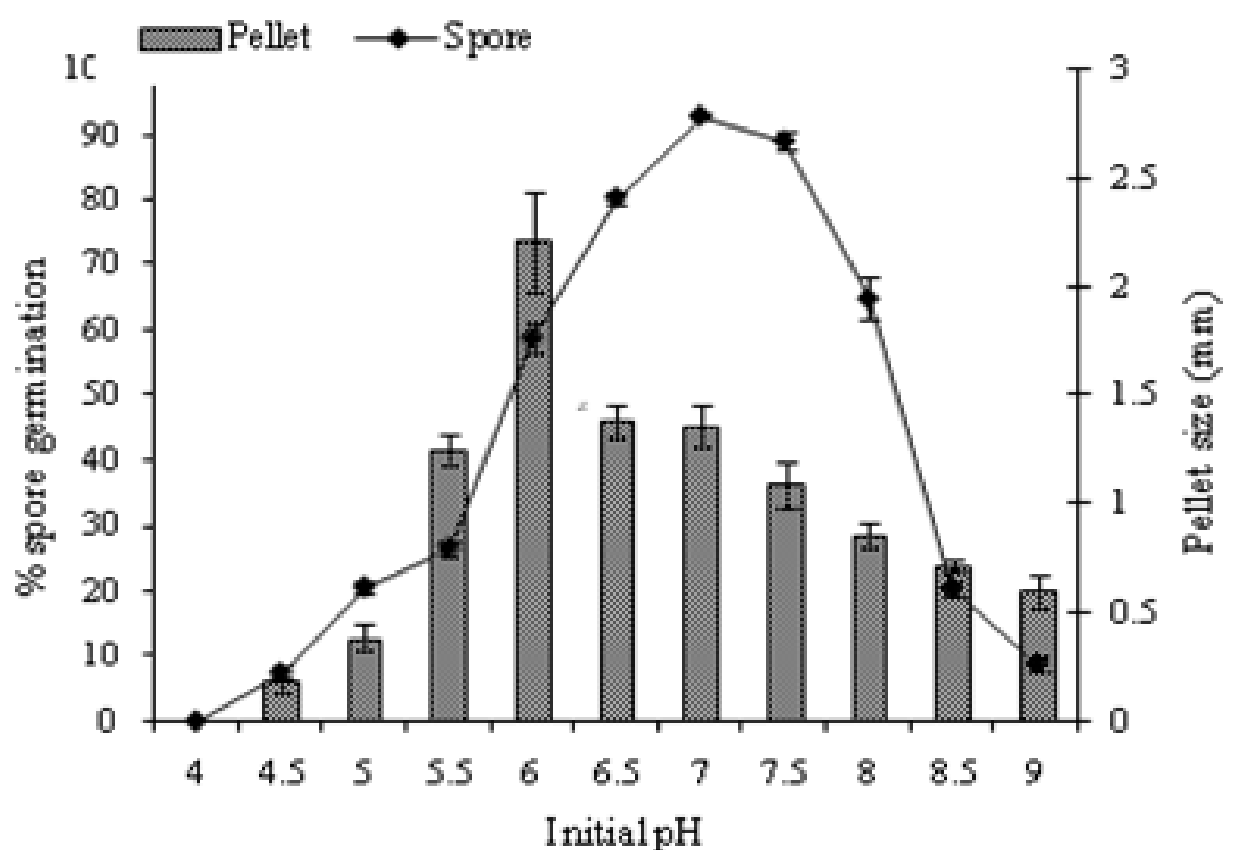

Figure 3a. Effect of initial $\mathrm{pH}$ of inoculum development broth on the spore germination, and pellet size.

space and did not translate into more amount of biomass and saw a significant decrease in Nigerloxin production (Figure 2b). In fact, the biomass produced above 500 $\mu / / L$, at around $50 \mathrm{~g} / \mathrm{L}$, was the same till $800 \mu / / \mathrm{L}$, whereas nigerloxin fell below $2 \mathrm{mg} / \mathrm{g}$ dry wheat bran. These results are in agreement with that of Van Suijdam et al. (1980) and Calam (1987) where higher concentration of spore suspension failed to produce pellets and suspension form of inoculum was produced. The highest Nigerloxin concentration was produced by using $500 \mu \mathrm{l} / \mathrm{L}$ inoculum broth spore suspension which yielded $5.81 \pm 0.04 \mathrm{mg} / \mathrm{g}$ dry wheat bran. Hence, $500 \mu \mathrm{l} / \mathrm{L}$, from the stock of $7 \times 10^{9} / \mathrm{ml}$ spores concentration was standardized for the rest of the experiments.

\section{Effect of $\mathrm{pH}$}

The effect of initial pH of inoculum medium on pellet size, spore germination and biomass production was studied by adjusting the $\mathrm{pH}$ of the broth from 2.0 to 9.0 (Figure 3a). It was observed that spore germination was less than $20 \%$ below $\mathrm{pH} 5$ and above 8.5 with the highest germination of $92 \%$ at $\mathrm{pH} 7$. Further, as $\mathrm{pH}$ increased from 4 to 7 , there was an increase in pellet size but interestingly, the pellet size over the entire $\mathrm{pH}$ spectrum tested was less than $1.5 \mathrm{~mm}$, except for $\mathrm{pH} 6.0$ where it reached $2.4 \mathrm{~mm}$. Production of biomass of $40-53 \mathrm{~g} / \mathrm{L}$ was seen between pH 5.5 to 7.0 with a complete absence at
$\mathrm{pH} 4$ and a slight increase between $\mathrm{pH} 4.5$ to 5 . There seems to be a correlation between spore germination and biomass production rather than with pellet size. The phenomenon of pellet formation being strongly influenced by $\mathrm{pH}$ is in agreement with the result of Galbraith and Smith and Carlsen et al. (1969, 1995). There was a complete absence of nigerloxin production by SSF when inoculum was developed below $\mathrm{pH} 5$ (Figure $3 \mathrm{~b}$ ). The highest nigerloxin production of $5.7 \mathrm{mg} / \mathrm{g}$ dry wheat bran was observed at pH 6.5 after which it fell drastically.

\section{Effect of temperature}

Temperature plays an important role in the development of pellets in inoculum medium and spore germination in solid state fermentation (Estrada et al., 2000). It was seen that spore germination below 20 and above $40^{\circ} \mathrm{C}$ was less than $30 \%$ increasing to $91 \%$ at $30^{\circ} \mathrm{C}$ (Figure 4a). A similar pattern was observed with pellet size formation in the range of 1.2 to $1.3 \mathrm{~mm}$ between 25 and $35^{\circ} \mathrm{C}$ and around $0.4 \mathrm{~mm}$ at the extreme temperatures tested. Unlike the results seen in initial $\mathrm{pH}$ of the medium, biomass produced correlated to both spore germination and pellet sizes. The highest biomass produced was 58 $\mathrm{g} / \mathrm{L}$ inoculum broth at $30^{\circ} \mathrm{C}$. The absence in nigerloxin production was seen in both extreme ends of temperature and the highest nigerloxin was at $30{ }^{\circ} \mathrm{C}$ which produced $5.76 \pm 0.07 \mathrm{mg} / \mathrm{g}$ dry wheat bran (Figure $4 \mathrm{~b}$ ). 


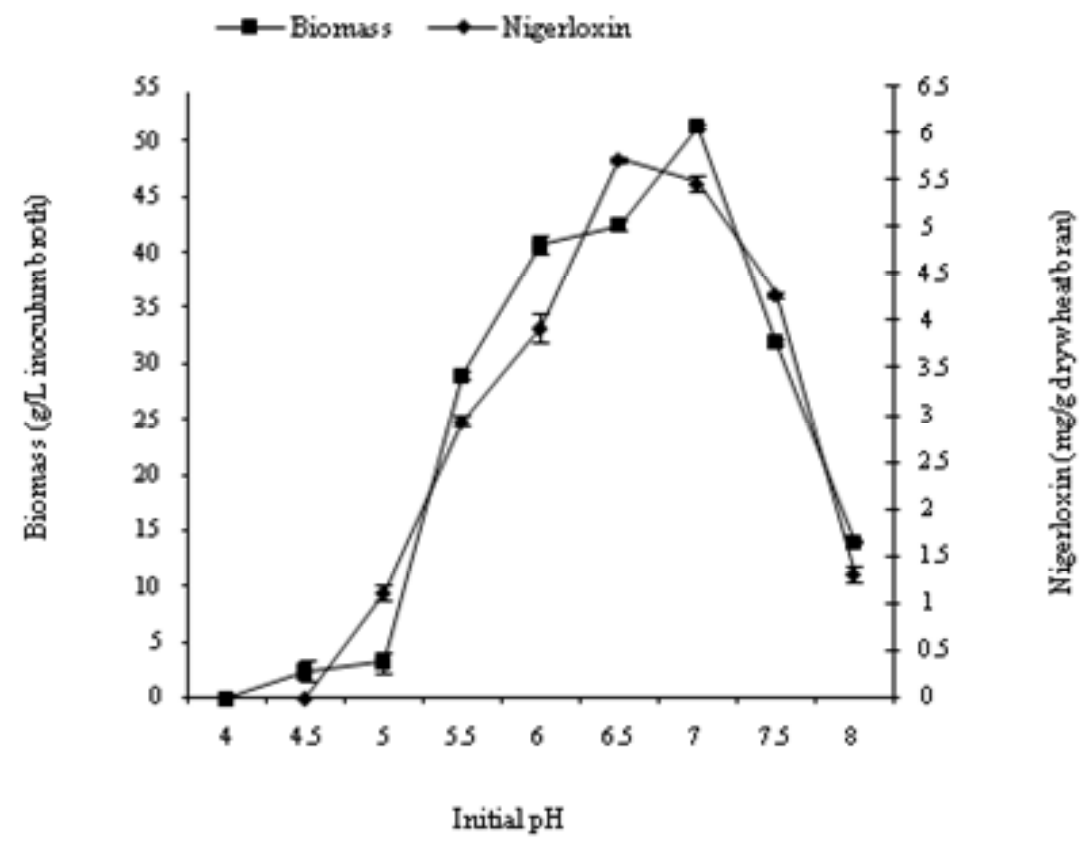

Figure 3b. Effect of initial pH of inoculum development broth on the production of biomass and nigerloxin.

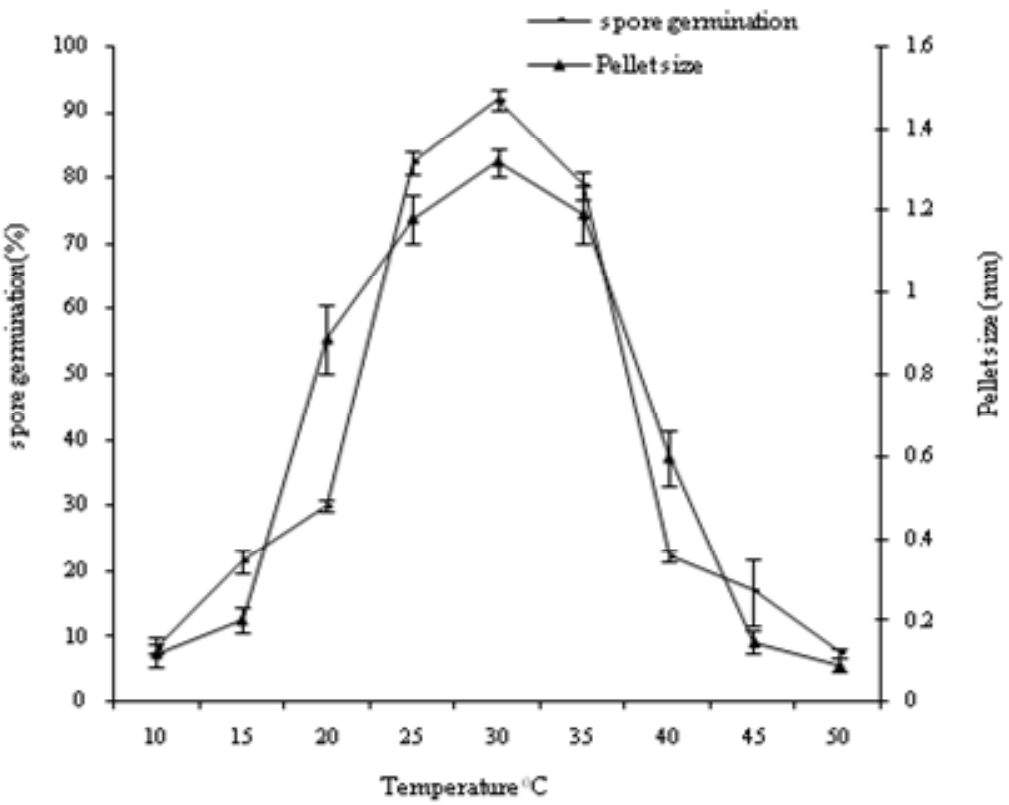

Figure 4a. Effect of incubation temperature of inoculum development broth on spore germination, and pellet size

\section{Effect of agitation}

Agitation is the by far the most important physical parameter in inoculum development for SS. Hence the effect of agitation condition on pellet size and spore germination was studied in inoculum broth and nigerloxin production in SSF.

Interestingly, the spore germination remained almost the 


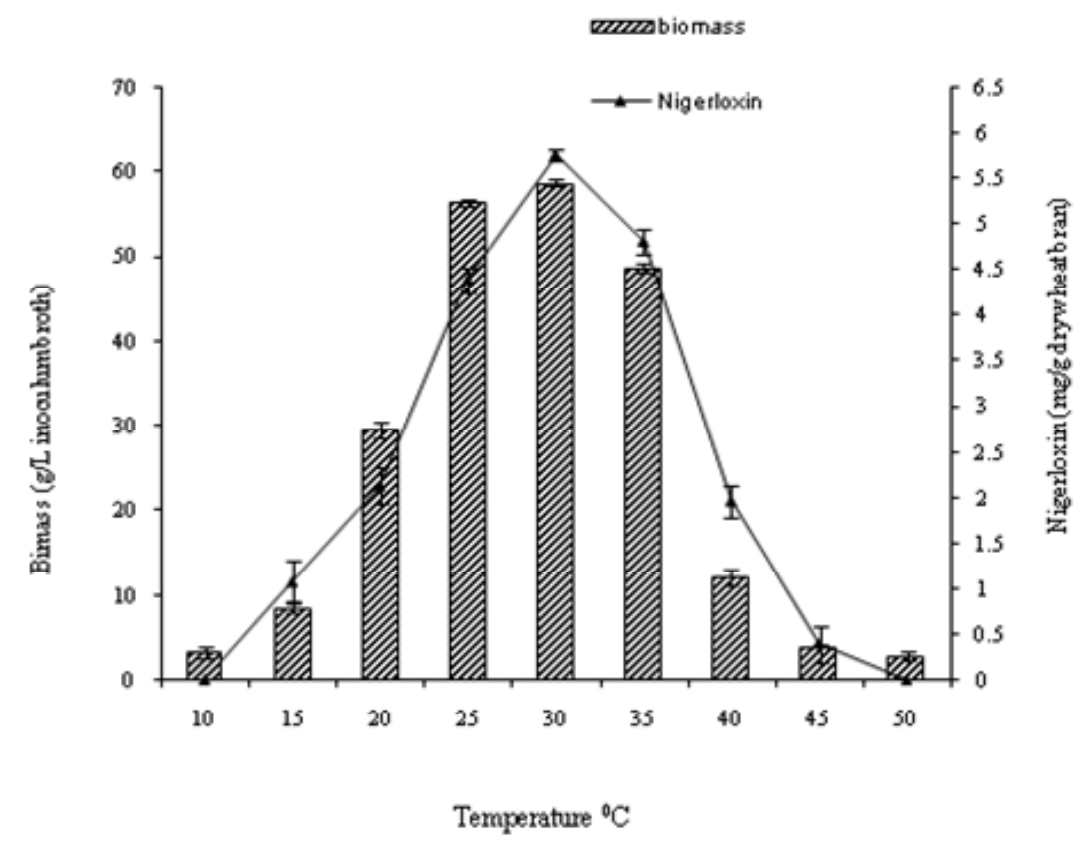

Figure 4b. Effect of incubation temperature of inoculum development broth on biomass and nigerloxin production.

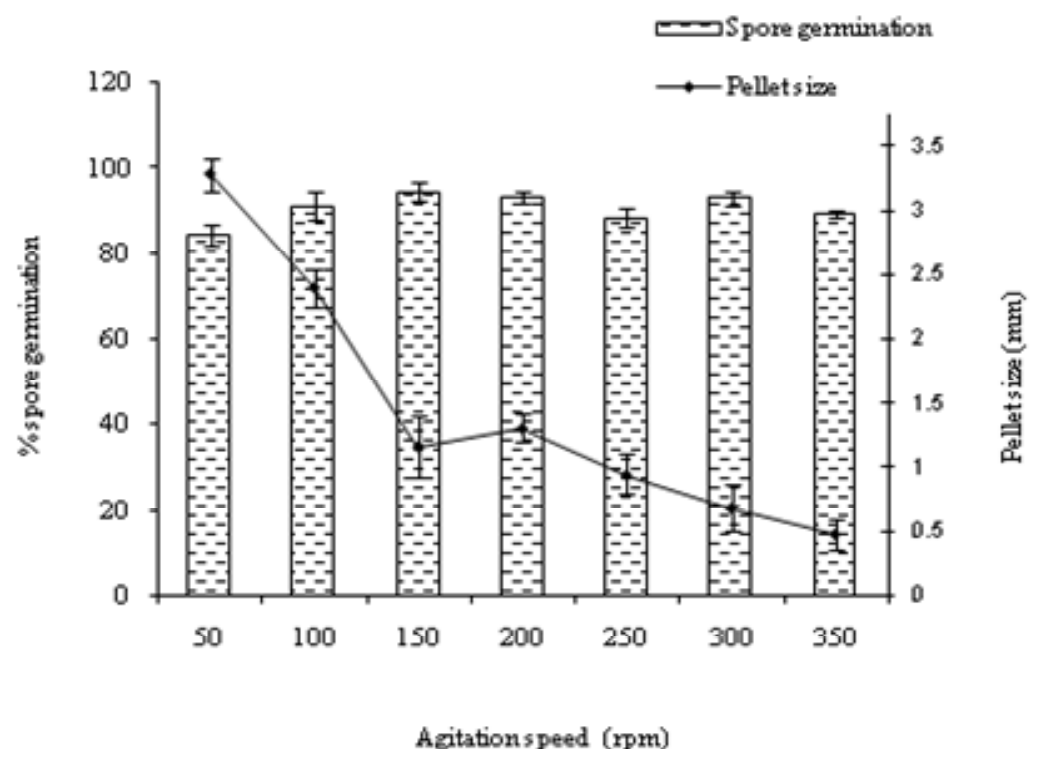

Figure 5a. Effect of agitation condition of inoculum development broth on spore germination, and pellet size

same in all agitation speeds employed with the highest at $93 \%$ at $200 \mathrm{rpm}$, whereas pellet sizes fell steadily from the highest of $3.2 \mathrm{~mm}$ at $50 \mathrm{rpm}$ to $0.5 \mathrm{~mm}$ at $350 \mathrm{rpm}$ (Figure 5a). Further, biomass produced was more than $40 \mathrm{~g} / \mathrm{L}$ under all ranges of agitation conditions. The highest production of nigerloxin was observed at $200 \mathrm{rpm}$ which yielded $6 \mathrm{mg}$ nigerloxin/g dry wheat bran (Figure 5b).

The optimized inoculum condition for the better production of nigerloxin was at $500 \mu \mathrm{l}$ of spore 


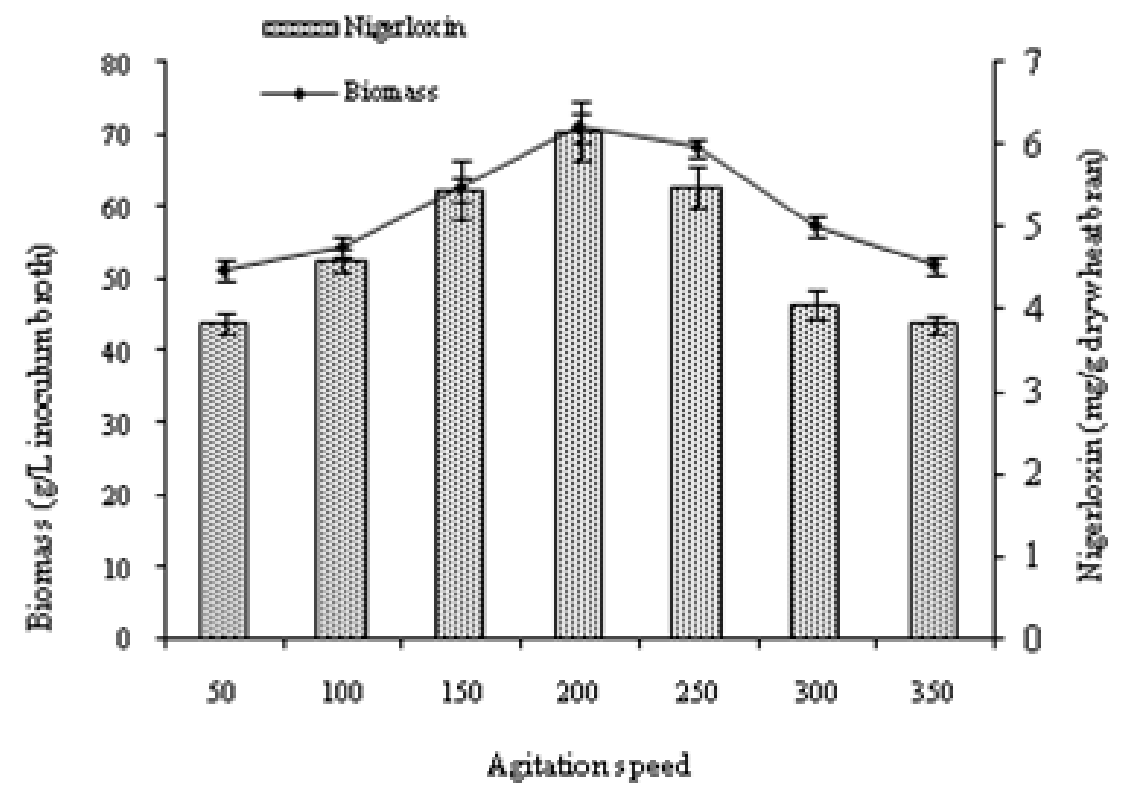

Figure 5b. Effect of agitation condition of inoculum development broth on biomass and nigerloxin production.

suspension in the inoculum development broth at $\mathrm{pH} 7$, incubated at $30{ }^{\circ} \mathrm{C}$ and $200 \mathrm{rpm}$ gave an ideal pellet size of $1.23 \mathrm{~mm}$ resulting in $6.0 \mathrm{mg}$ of nigerloxin/g dry weight of wheat bran in SSF.

Production of secondary metabolite from microorganism is a complex task as they require a number of optimal conditions. Inoculum is one of such factors, which if not optimized, may lead to poor or absence of desired product yield. The successful production of a fungal metabolite requires knowledge of the growth characteristics and the physiology of the fungus in question. Thus, for each fermentation, the precise physiological condition and optimised media for inoculum development must be established. The present work was an attempt to understand the type of inoculum conditions required to enhance the production of nigerloxin in solid state fermentation using controlled wheat bran medium by $A$. niger CFTR-W-105. The data generated in this study would be helpful in producing nigerloxin on large scale and has the potential for further developing it into a powerful therapeutic molecule against diabetic complications.

\section{Conflict of Interests}

The author(s) have not declared any conflict of interests.

\section{ACKNOWLEDGEMENT}

The authors thank the Department of Biotechnology, New
Delhi, India for financial support. VKY thanks CSIR for a Senior Research Fellowship award.

\section{REFERENCES}

Braun KL (1971). Spore germination time in Fuligo septica. The Ohio. J. Sc. 71:305-309.

Calam CT (1987). Process development in antibiotic fermentations. Cambridge Studies in Biotechnology, vol. 4. Cambridge: Cambridge Univ. Press.

Carlsen M, Spo"hr AB, Nielsen J, Villadsen J (1995). Morphology and physiology of an a-amylase producing strain of Aspergillus oryzae during batch cultivations. Biotechnol. Bioeng. 49:266-276.

Chakradhar D, Saleem J, Sattur AP (2009). Studies on the production of nigerloxin using agro industrial residues by solid-state fermentation. J. Ind. Microbiol. Biotechnol. 36:1179-1187.

Estrada AB, Dodd JC, Jeffries P (2000). Effect of humidity and temperature on conidial germination and appressorium development of two Philippine isolates of the mango anthracnose pathogen olletotrichum gloeosporioides. Plant Pathol. 49:608-618.

Galbraith JC, Smith JE (1969). Filamentous growth of Aspergillus niger in submerged shake culture. Trans. Brit. Mycol. Soc. 52:237-246.

Hockenhull DJD (1980). Inoculum development with particular reference to Aspergillus and Penicillium, in: Smith, JE, Berry DR, Kristiansen B (Eds.), Fungal biotechnology, Academic press, New York, pp. 1-24.

Papagianni M, Moo-Young M (2002). Protease secretion in glucoamylase producer Aspergillus niger cultures: fungal morphology and inoculum effects. Process. Biochem. 37:1271-1278.

Pazouki M, Panda T (2000). Understanding the morphology of fungi. Bioprocess. Eng. 22:127-143.

Rao KCS, Divakar S, Babu KN, Karanth NG, Sattur AP (2002). Nigerloxin, a novel inhibitor of aldose reductase and lipoxygenase with free radical scavenging activity from Aspergillus niger CFR-W105. J. Antibiotic. 55:789-793.

Rao KCS, Karanth NG, Sattur AP (2005). Production of nigerloxin, an enzyme inhibitor and a free radical scavenger, by Aspergillus niger using solid state fermentation. Process Biochem. 40(7):2517-2522. 
Suresh BS, Vasantha KY, Sattur AP, Srinivasan K (2013). Beneficial influence of fungal metabolite nigerloxin on diabetes-induced oxidative stress in experimental rats. Can. J. Physiol. Pharmacol. 91(2):149-156

Suresh BS, Sattur AP, Srinivasan K (2012). Beneficial influence of fungal metabolite nigerloxin on eye lens abnormalities in experimental Diabetes. Can. J. Physiol. Pharmacol. 90(4):387-394.
Van Suijdam JC, Kossen NWF, Paul PG (1980). An inoculum technique for the production of fungal pellets. Eur. J. Appl. Microbiol. Biotechnol. 10:211-221. 